\title{
Tuberculosis among COPD Patients in Guba City, Azerbaijan
}

\author{
Amir V. Aliyev, Rafig A. Chobanov \\ Azerbaijan Medical University, Baku, Azerbaijan \\ Email: amirvugar@mail.ru
}

Received 7 November 2015; accepted 8 December 2015; published 11 December 2015

Copyright @ 2015 by authors and Scientific Research Publishing Inc.

This work is licensed under the Creative Commons Attribution International License (CC BY).

http://creativecommons.org/licenses/by/4.0/

(c) (i) Open Access

\begin{abstract}
Chronic obstructive pulmonary disease (COPD) retains their relevance. It is necessary to take into account that growth in the number of patients with lung diseases. In addition, there is a growth in the number of tuberculosis patients. According to the criteria of the Ministry of Health, patients with COPD are at risk.
\end{abstract}

\section{Keywords}

\section{COPD, Tuberculosis, Screening}

\section{Introduction}

\subsection{Purpose}

Chronic obstructive pulmonary disease occurs frequently in patients with tuberculosis, particularly in men older than 40 years. Thus, COPD can be para-, meta-, and post-tuberculosis process [1]-[4]. Both diseases have similar risk factors: smoking, low socio-economic status of the individual and the violation of the immune defense [5]-[7]. A related aspect of the above pathogenetic nosology is the development of destructive changes in the pulmonary parenchyma, caused, in particular, a metabolic disorder due to exposure to tobacco metalloproteinases or virulence factors Mycobacterium tuberculosis [2] [5] [8]. Among the diseases found at autopsy in patients who died of TB in Texas (USA) from 2000 to 2010, COPD was in 5th place [4] [9]. Paratuberculous process data in this study are not separately isolated. At the same time, the experience of some authors shows that among all causes of hospitalization in infectious department of patients with this pathology tuberculosis occupies a significant place, second only to respiratory tract infections and pyothorax [1] [9] [7] [10]. There is a high probability of death of the patient within one year from the date of detection of tuberculosis-according to different authors varies between $18 \%$ - 22\% of all cases [6] [9]-[11].

The aim of this study is to study the epidemiology and course of pulmonary tuberculosis that develops in pa- 
tients suffering from COPD in the long time, at the time of the identification process.

\subsection{Methods}

The study included randomized selected 110 COPD patients in whom TB was diagnosed from 2009 to 2014 . The mean age is $50 \pm 3$ years. The period from the time of the first visit to a doctor about COPD before the detection of tuberculosis was $4 \pm 1$ year.

According to the method of "copy pair" in the control group were selected 110 men with active tuberculosis, and discovered from 2009 to 2014. COPD they did not have.

All patients, in addition to clinical examination, X-ray examination was carried out using high resolution computed tomography, spirometry, bronchoscopy, laboratory and bacteriological tests, sputum culture on solid nutrient media and identification of drug resistance in Mycobacterium tuberculosis (MBT). The period of follow-up was 2.5 years.

\subsection{Data Analysis}

Statistical analysis used the software package Statistica 8.0 for Windows. Calculation of the following statistical values: probability of an event $\mathrm{P}, 85 \%$ confidence interval for the probability of an event $\mathrm{l} \beta$, $\mathrm{z}$ test for comparing qualitative variables, $\mathrm{x}^{2}$ Pearson, the significance level of $\mathrm{p}$ (considered statistically significant $\mathrm{p}<0.05$ ), the correlation coefficient for $\varphi$ dichotomous data.

\subsection{Ethics}

Ethical approval was sought from the Azerbaijan Doctors Training Institute (ADTI) and subsequently from Azerbaijan Republican Epidemiology Center (AREC).

\section{Results}

Patients with COPD were found the following forms of TB: focal-6 (5.5\%), infiltrative-59 (53.6\%), disseminated-33 (30\%), fibrocavernous-12 (10.9\%). When planning investigation identified 84 ( $\mathrm{P}=0.764 ; 1 \beta \approx$ 0.706; 0.822), the rest—on the uptake. In the control group the ratio is similar forms. When planned examination revealed 45 ( $\mathrm{P}=0.409 ; 1 \beta \approx 0.342 ; 0.476)$ people, which is significantly lower than in the study group ( $\mathrm{p}<$ 0.05).

Prior fluorography conducted in the following periods: one year to identify-45 (40.9\%) cases, 2 - 3 years56 (50.9\%), four years -7 (6.3\%), data were missing - 2 (19\%). The great majority of patients were chest Xrays of the chest for 1 - 3 years before the detection of tuberculosis $(P=0.918 ; 1 \beta \approx 0.880 ; 0.956)(\mathrm{p}<0.0001)$, while among those with fibrocavernous process $6(50 \%)$ They were examined 2 - 3 years ago. In the control group prior x-ray screenings were performed on the following dates: one year to identify-30 (27.3\%) cases, 2 3 years -52 (47.3\%), 4 years $-20(18.2 \%)$, the data absent -8 (7.2\%). Statistically significant differences in the timing of the previous survey fluorography are not obtained $(\mathrm{p}<0.05)$. All persons with fibro-cavernous tuberculosis were not surveyed four years ago or longer.

All patients had a smoking history of more than 40 packs/year (the average length of 49/year), but steadfastly refused to smoking at the beginning of TB treatment, 52 people $(\mathrm{P}=0.473 ; 1 \beta \approx 0.404 ; 0.542)$. In the control group there were patients who had never smoked-8 (7.2\%) refused to smoking-39 (35.5\%) continued smoking 63 (57.3\%). The average length of smoking was 25 packs/year, which was lower than the main group $(\mathrm{p}<0.05)$.

Forced expiratory volume (FEV1) was in the range 80\% - 50\% in $39(35.5 \%)$ patients, $49 \%-30 \%-62$ (56.4\%), less than 30\%-9 (8.1\%). The ratio of FEV1/FVC ratio was less than $70 \%$ for all patients. Regular treatment of COPD in accordance with clinical guidelines of Ministry of Health of the Republic received 36 patients $(\mathrm{P}=0.327 ; 1 \beta \approx 0.263 ; 0.391)$, low kompleans occurred in 52 cases $(\mathrm{P}=0.473 ; 1 \beta \approx 0.404 ; 0.542)$, inadequate treatment due to the severity of the medical recommendations established in 22 cases $(\mathrm{P}=0.200 ; 1 \beta \approx$ $0.145 ; 0.255$ ). Disability due to COPD were only 20 patients $(\mathrm{P}=0.189 ; 1 \beta \approx 0.135 ; 0.243)$. In the control group FEV1 was normal in 93 (84.5\%) patients within 80\% - 50\% - in 17 (15.5\%). The ratio of FEV1/FVC ratio was over $70 \%$ in all patients. Samples with Diasketine performed at 71 people, a negative result was obtained in 44 $(\mathrm{P}=0.619 ; 1 \beta \approx 0.553 ; 0.685)$. The destructive tuberculosis had 100 patients $(\mathrm{P}=0.909 ; 1 \beta \approx 0.870 ; 0.948)$. Bacterio excretion observed in 85 patients $(\mathrm{P}=0.773 ; 1 \beta \approx 0.716 ; 0.830)$, while at the paucibacillary—38 $(\mathrm{P}=$ 
$0.345 ; 1 \beta \approx 0.280 ; 0.410)$. Primary drug resistance -2 ( $\mathrm{P}=0.018 ; 1 \beta \approx 0.000 ; 0.036)$. In the control group test with Diasketine put at 79 people, a negative result was recorded in $11(\mathrm{P}=0.100 ; 1 \beta \approx 0.059 ; 0.141)$, which gives an indicator of the main group $(\mathrm{p}<0.05)$. The destructive tuberculosis occurred in 100 patients in the control group $(\mathrm{P}=0.909 ; 1 \beta \approx 0.706 ; 0.822)$. Bacterioexcretion reported in 102 patients $(\mathrm{P}=0.927 ; 1 \beta \approx 0.891$; $0.963)$, while paucibacillary $-13(\mathrm{P}=0.118 ; 1 \beta \approx 0.074 ; 0.162)$. The difference between the two groups was on the basis of a statistically significant $(\mathrm{p}<0.05)$. Primary drug resistance $-4(\mathrm{P}=0.036 ; 1 \beta \approx 0.010 ; 0.062)(\mathrm{p}<$ $0.05)$.

In 39 patients ( $\mathrm{P}=0.354 ; 1 \beta \approx 0.288 ; 0.420$ ) during bronchoscopy established signs of purulent bronchitis. In the control group, the signs of purulent bronchitis found in 30 people $(\mathrm{P}=0.273 ; 1 \beta \approx 0.212 ; 0.334)(\mathrm{r}>0.1)$.

All patients assigned to chemotherapy according to clinical guidelines and orders of the Ministry of Health of Azerbaijan Republic. Positive clinical and radiological improvement was achieved in 61 patients $(\mathrm{P}=0.555 ; 1 \beta \approx$ $0.487 ; 0.623)$. The outcome in cirrhotic form occurred in one patient $(\mathrm{P}=0.009 ; 1 \beta \approx 0.000 ; 0.018)$. In 43 patients $(\mathrm{P}=0.391 ; 1 \beta \approx 0.324 ; 0.458)$ infiltrative and disseminated tuberculosis marked progression of the process and the development of fibro-cavernous shape, in 6 patients with fibro-cavernous tuberculosis $(\mathrm{P}=$ $0.055 ; 1 \beta \approx 0.024 ; 0.086$ ) failed to reach a clinically significant effect. Not observed 11 chemotherapy regimen $(\mathrm{P}=0.100 ; 1 \beta \approx 0.059 ; 0.141)$, not regular use inhalation therapy of COPD $40(\mathrm{P}=0.364 ; 1 \beta \approx 0.298 ; 0.430)$. In 65 patients $(\mathrm{P}=0.591 ; 1 \beta \approx 0.524 ; 0.658)$, in addition to the caverns, there were multiple lung bullae, usually in the upper right side $-44(\mathrm{P}=0.400 ; 1 \beta \approx 0.333 ; 0.467)$. Established a significant correlation between the presence of bullosa changes and the development of fibro-cavernous TB $(\varphi=0.6754 ; \mathrm{r}<0.05)$. Bacteriological proof was achieved in $52(61.2 \%)$ patients $(\mathrm{P}=0.472 ; 1 \beta \approx 0.404 ; 0.540)$. Patients with paucibacillary in the development of chronic forms of tuberculosis appear massive bacteria. In 15 patients $(\mathrm{P}=0.136 ; 1 \beta \approx 0.089$; $0.183)$, to allocate initially sensitive to first-line chemotherapy drugs Mycobacterium TB, 9 patients $(\mathrm{P}=0.082$; $1 \beta \approx 0.044 ; 0.120$ ) is held for 2 years. He died of tuberculosis in the stated period of observation 2 patients, one of them a year after the start of chemotherapy.

In the control group, the positive clinical and radiological improvement was achieved in 85 people $(\mathrm{P}=0.773$; $1 \beta \approx 0.716 ; 0.830$ ). The progression of the process or lack of effect noted in 25 patients $(\mathrm{P}=0.227 ; 1 \beta \approx 0.170$; $0.284)$, which was significantly lower than in the study group $(\mathrm{r}<0.05)$. Not observed 21 people chemotherapy regimen ( $\mathrm{P}=0.191 ; 1 \beta \approx 0.137 ; 0.245)$, which exceeds the figure of the main group, but not statistically significant $(\mathrm{r}>0.05)$. Proof of bacteriological succeeded in significantly more patients-79 $(77.4 \%)(\mathrm{P}=0.718 ; 1 \beta \approx$ $0.656 ; 0.780)(\mathrm{r}<0.05)$. In 3 patients $(\mathrm{P}=0.027 ; 1 \beta \approx 0.005 ; 0.049)$, initially allocates the Mycobacterium TB, in 12 patients $(\mathrm{P}=0.109 ; 1 \beta \approx 0.066 ; 0.152)$ it was formed within 2 years. The main group of drug resistance has developed much earlier and more often $(\mathrm{r}<0.05)$. He died of tuberculosis in the control group of 5 people in the follow-up of greater than one year and revealed a high correlation between the absence of the patient due bronchodilator therapy and development of fibro-cavernous TB $(\varphi=0.7564 ; \mathrm{r}<0.05)$. At the same time such a link between the violation of the chemotherapy and the formation of the chronic form of the main group were observed ( $\varphi=0.3547 ; \mathrm{r}<0.05)$, although it took place in the control $(\varphi=0.8123 ; \mathrm{r}<0.05)$. It is interesting that a significant correlation is determined between the development of chronic forms of tuberculosis and the initial value of FEV1 49\% - 30\% ( $\varphi=0.5879 ; \mathrm{r}<0.05)$.

\section{Conclusions}

Tuberculosis in patients with COPD main cases is detected by x-ray screenings planned. Using other common ways of detection of tuberculosis is difficult, as it is common in COPD and pauci- or abatsillarity, negative tests with Diaskintest. Current TB patients in this category often lead to rapid development of chronic forms and formation of drug resistance, which is caused by the lack of adequate bronchodilator therapy, as well as the features of the functional and morphological changes at the same time.

An important practical step was that organizational health would permit TB physicians to prescribe to free modern drugs for the treatment of COPD in patients with tuberculosis, as well as the practical application of general health services twice annual fluorography examination of patients with COPD.

\section{Acknowledgements}

The authors sincerely thank the staff of the Azerbaijan Doctors Training Institute (ADTI) and subsequently from Azerbaijan Republican Epidemiology Center (AREC) for their technical guidance and routine collection of the 
data used in this operations research.

\section{Conflict of Interest}

None of the authors have a commercial or other financial interest associated with the information presented in this manuscript.

\section{References}

[1] Aliyev A.V. (2015) Quality Criteria for Tuberculosis Care Dispensary Stage. Problems of Biology \& Medicine, 3, 116120.

[2] Balbay, E.G., Binay, S., Suner, K.O., et al. (2014) Do We Question Occupational and Environmental Exposure Adequately in the Outpatient Clinic of Chest Diseases? Eurasian Journal of Pulmonology, 16, 130-132. http://dx.doi.org/10.5152/ejp.2014.04557

[3] Basic, Z., Fox, A.R., Anteric, I., et al. (2015) Cultural Inter-Population Differences Do Not Reflect Biological Distances: An Example of Interdisciplinary Analysis of Populations from Eastern Adriatic Coast. Croatian Medical Journal, 56, 230-238. http://dx.doi.org/10.3325/cmj.2015.56.230

[4] Chobanov, R.A. and Aliyev, A.V. (2014) Analysis of the Incidence of COPD Inpatients Seen at the Central Hospital of the Guba Region of Azerbaijan for 2012-2013 Years. proceedings of the 2nd International Conference "Modern Problems of Management: Economics, Education, Health Care and Pharmacy”, 23-27 October 2014, Opole, 192-194.

[5] French, C.T., Diekemper, R.L. and Irwin, R.S. (2015) Assessment of Intervention Fidelity and Recommendations for Researchers Conducting Studies on the Diagnosis and Treatment of Chronic Cough in the Adult: CHEST Guideline and Expert Panel Report. Chest, 148, 32-54. http://dx.doi.org/10.1378/chest.15-0164

[6] Garrow, A.P., Khan, N., Tyson, S., et al. (2015) The Development and First Validation of the Manchester Early Morning Symptoms Index (MEMSI) for Patients with COPD. Thorax, 170, 757-763. http://dx.doi.org/10.1136/thoraxjnl-2014-206410

[7] Jimenas-Ruiz, C.A., Andreas, S., Lewis, K.E., et al. (2015) Statement on Smoking Cessation in COPD and Other Pulmonary Diseases and in Smokers with comorbidities Who Find It Difficult to Quit. European Respiratory Journal, 46, 61-79. http://dx.doi.org/10.1183/09031936.00092614

[8] Martinez, C.H., Mannino, D.M., Curtis, J.L., et al. (2015) Socioeconomic Characteristics Are Major Contributors to Ethnic Differences in Health Status in Obstructive Lung Disease: An Analysis of the National Health and Nutrition Examination Survey 2007-2010. Chest, 148, 151-158. http://dx.doi.org/10.1378/chest.14-1814

[9] Miller, M.R. and Levy, M.L. (2015) Chronic Obstructive Pulmonary Disease: Missed Diagnosis versus Misdiagnosis. British Medical Journal, 351, h3021. http://dx.doi.org/10.1136/bmj.h3021

[10] Shmelev, E.I., Kuklina, G.M., Yakimova, M.A., et al. (2010) Pulmonary Tuberculosis and Underlying Respiratory Pathology. Pulmonology, 5, 38-40

[11] Zhang, X., Holt, J.B., Yun, S., et al. (2015) Validation of Multilevel Regression and Poststratification Methodology for Small Area Estimation of Health Indicators from the Behavioral Risk Factor Surveillance System. American Journal of Epidemiology, 182, 127-137. http://dx.doi.org/10.1093/aje/kwv002 